\title{
Inspiratory Capacity as an Indirect Measure of Immediate Effects of Positive Expiratory Pressure and CPAP Breathing on Functional Residual Capacity in Healthy Subjects
}

\author{
Maria Sehlin PhD RPT, Ola Winsö PhD MD, Karin Wadell PhD RPT, and Fredrik Öhberg PhD
}

\begin{abstract}
BACKGROUND: Positive expiratory pressure (PEP) and CPAP are used to enhance breathing parameters such as functional residual capacity (FRC) in patients. Studies comparing effects of PEP and CPAP on FRC are few and variable. One reason for this may be that sophisticated equipment, not suitable in the clinical setting, is required. Because total lung capacity (TLC) consists of inspiratory capacity (IC) and FRC, a change in IC should result in a corresponding change in FRC given constant TLC. We aimed to evaluate the effects of different PEP and CPAP devices on IC as an indirect measure of induced changes in FRC from these devices in healthy subjects. METHODS: Twenty healthy subjects breathed with 2 PEP devices, a PEP mask (flow resistor) and a PEP bottle (threshold resistor), and 2 CPAP devices, a flow resistor and a threshold resistor, in a randomized order. The measurement sequence consisted of 30 breaths with an IC measurement performed before and immediately after the 30th breath while the subjects were still connected to the breathing device. Perceived exertion of the 30 breaths was measured with the Borg category ratio 10 scale. RESULTS: Three of the 4 breathing devices, the PEP mask and the 2 CPAP devices, significantly decreased IC $(P<.001)$. Median perceived exertion was quite low for all 4 breathing devices, but the difference in perceived exertion among the different breathing devices was large. CONCLUSIONS: Provided that TLC is constant, we found that measurements of changes in IC could be used as an indirect measure of changes in FRC in healthy subjects. All investigated breathing devices except the PEP bottle decreased IC, as an indirect measure of increased FRC. Key words: PEP; CPAP; threshold resistor; flow resistor; inspiratory capacity; Borg CR10 scale. [Respir Care 2015;60(10):1486-1494.

(C) 2015 Daedalus Enterprises]
\end{abstract}

\section{Introduction}

Positive expiratory pressure (PEP) is an airway clearance technique involving breathing out against a resis-

\footnotetext{
Drs Sehlin and Winsö are affiliated with the Department of Surgical and Perioperative Sciences, Anesthesiology and Intensive Care Medicine, Drs Sehlin and Wadell are affiliated with the Department of Community Medicine and Rehabilitation, Physiotherapy, and Drs Sehlin and Öhberg are affiliated with the Department of Radiation Sciences, Biomedical Engineering, Umeå University, Umeå, Sweden.

Dr Sehlin presented a version of this paper as part of a $\mathrm{PhD}$ dissertation on November 7, 2014, in Umeå, Sweden.

This study was supported by grants from the Västerbotten County Council. The threshold resistor CPAP device (O2-RESQ system) was provided by IM-Medico Svenska (Saltsjö-Boo, Sweden). The authors have disclosed no other conflicts of interest.
}

tance. The resistance increases airway pressure during the expiratory phase compared with normal expiration. Because inhalation is done without any aid, airway pressure is negative, as during a normal inspiration. Two different categories of resistors are used: threshold resistors and flow resistors. ${ }^{1,2}$ To obtain air flow through a threshold resistor device, an airway pressure higher than the chosen PEP has to be established before exhalation occurs. With a flow resistor, expiratory pressure is determined by air

\footnotetext{
Correspondence: Maria Sehlin PhD RPT, Department of Surgical and Perioperative Sciences, Anesthesiology and Intensive Care Medicine, University Hospital of Umeå, 90185 Umeå, Sweden. E-mail: maria.sehlin@umu.se.
}

DOI: $10.4187 /$ respcare.03872 
flow and the diameter of the resistor, and air flow starts at the beginning of the exhalation. ${ }^{3}$ PEP with a threshold resistor (a spring-loaded valve) is sometimes referred to as expiratory positive airway pressure (EPAP). ${ }^{4}$

CPAP means spontaneous breathing at an elevated pressure. Unlike PEP, where airway pressure is negative during inhalation, breathing with CPAP keeps the airway pressure positive throughout the respiratory cycle. The positive airway pressure can, in the same manner as with PEP, be accomplished by either a threshold or flow resistor. ${ }^{1,2}$ Regardless of the resistor, the velocity of air-flow delivered by a CPAP device to the patient needs to be higher than the patient's peak inspiratory air flow to minimize work of breathing. ${ }^{5}$

Beneficial effects of PEP and CPAP are thought to be mediated by changes in functional residual capacity (FRC). Most often, both PEP and CPAP increase FRC, thereby improving pulmonary gas exchange. ${ }^{6-9}$ However, PEP and CPAP may also be used to decrease FRC in patients with hyperinflation, as in COPD. ${ }^{10,11}$ Studies comparing effects of PEP and CPAP on FRC are few, have variable results, ${ }^{12-14}$ and require methods that are difficult to use in clinical situations because they require advanced equipment.

FRC and inspiratory capacity (IC) comprise the total lung capacity (TLC), and theoretically, an increase in FRC in response to PEP or CPAP breathing would be reflected as a decrease in IC. The prerequisite for this assumption is that TLC is constant. Because FRC is difficult to measure in clinical situations, measurement of IC was chosen as an indirect measure of FRC. IC has previously been used to measure hyperinflation in subjects with COPD. ${ }^{15,16} \mathrm{We}$ therefore designed this study for healthy subjects to evaluate the effects of different PEP and CPAP devices on IC as an indirect measure of induced changes in FRC. In addition, we wanted to evaluate the subjects' estimated perceived exertion when breathing with different PEP and CPAP devices.

\section{Methods}

The study was approved by the regional ethics review board in Umeå, and written informed consent was obtained from each subject.

\section{Subjects}

Twenty non-smoking healthy subjects (14 women and 6 men, $44 \pm 11$ y of age [mean $\pm \mathrm{SD}$ ]) were recruited and participated in the study. Inclusion criteria required the subjects to be $>18$ y old, have normal lung function, be able to read and write Swedish, and understand the consent form. The exclusion criteria were smoking, lung disease, and an ongoing cold. To ensure that the subjects had nor-

\section{QUICK LOOK}

\section{Current knowledge}

Positive expiratory pressure (PEP) and CPAP are frequently applied to increase functional residual capacity (FRC) and prevent or treat postoperative pulmonary complications. The passive rise in FRC is commonly assumed, as measurement at the bedside is time-consuming, difficult, and expensive. Methods to determine the impact of PEP and CPAP at the bedside are warranted.

\section{What this paper contributes to our knowledge}

In a group of healthy subjects using PEP and CPAP devices, if total lung capacity remained constant, measurements of changes in inspiratory capacity (IC) could be used as an indirect measure of changes in FRC. IC decreased significantly with 3 of the 4 breathing devices: the PEP mask and the flow and threshold resistor CPAP devices, but not the PEP bottle. The magnitude of the decrease in IC was the same with these 3 devices. Studies of subjects with disease are required to confirm findings in a clinically relevant scenario.

mal lung function, vital capacity and $\mathrm{FEV}_{1}$ was measured (SpiroTube Mobile Edition, THOR Medical Systems, Budapest, Hungary).

During all measurements, the subjects sat on an adjustable chair in front of an adjustable table. They were positioned with a $90^{\circ}$ flexion in their hips and knees, feet firmly placed on the floor, and elbows placed on the table. They were instructed to hold a face mask (Vygon, Skellefteå, Sweden) to the face with their hands. The face mask was used during all measurements, including the IC maneuvers.

IC

For IC measurements, the subjects were instructed to hold the face mask firmly against their faces. They were asked to take 3 normal quiet breaths, to breathe in as deeply as possible, and then to breathe out as a sigh followed by 4 normal quiet breaths (Fig. 1). ${ }^{17}$

\section{Experimental Equipment}

The equipment used is described in detail elsewhere. ${ }^{3,18}$ In brief, the PEP bottle is a threshold resistor device (water seal) consisting of a bottle filled with water and a tube with an inner diameter of at least $8 \mathrm{~mm} .{ }^{19}$ The PEP mask (Wellspect HealthCare, Mölndal, Sweden) is a flow resis- 


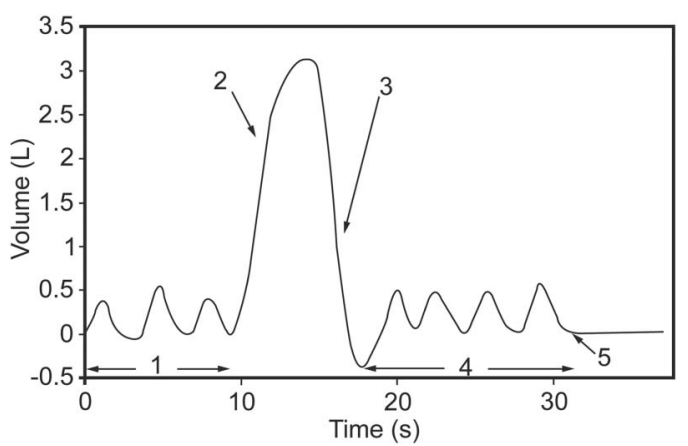

Fig. 1. Respiratory profile used when instructing inspiratory capacity maneuvers. 1: Three normal, quiet breaths. 2: Maximum inspiration. 3: Breathe out as a sigh. 4: Four normal quiet breaths. 5: Let go of the spirometer.

tor device (orifice resistor) consisting of a face mask, a $\mathrm{T}$-valve that separates inspiratory and expiratory air flow, and 8 different orifice resistors ranging from 1.0 to $6.0 \mathrm{~mm}$ in inner diameter. A manometer (Wellspect HealthCare) was used to measure expiratory pressures.

The O2-RESQ system (IM-Medico Svenska, SaltsjöBoo, Sweden) is a disposable threshold resistor CPAP device including a face mask; a preset spring-loaded valve adjustable to deliver a CPAP of 5, 7.5, or $10 \mathrm{~cm} \mathrm{H}_{2} \mathrm{O}$; an anti-asphyxia circuit; and a fixed-flow generator. The Boussignac CPAP system (Vygon) is a disposable flow resistor device including a face mask and a 5.5-cm-long plastic tube open to the atmosphere. The plastic tube has $4 \mathrm{mi}-$ crochannels, and air or oxygen is delivered into the microchannels with a flow meter. Gas flow accelerates through the microchannels, creating a virtual valve on the patient side of the plastic tube. ${ }^{20,21}$ The velocity of gas flow through the microchannels determines the size of the virtual valve and thereby CPAP, making this CPAP device flow-dependent.

\section{Experimental Setup}

The setup (Fig. 2) consisted of a face mask, a bacterial filter (BaktPLUS, Codan Triplus, Kungsbacka, Sweden), a pressure transducer (PMSET 1TNF-R, Becton Dickinson, Singapore), and an air-flow transducer (SS11LA, Biopac Systems, Goleta, California). The breathing device was connected at the distal end of the air-flow transducer.

During measurements with the 2 PEP devices, the Tvalve from the PEP mask was connected to the air-flow transducer. For the PEP bottle ( $82 \mathrm{~mm}$ in diameter), a metal tube (211 mm long with an inner diameter of $11 \mathrm{~mm}$ ) was connected to the expiratory limb of the T-valve. The PEP bottle was filled with water and weighed before every measurement to ensure that the amount of water was the same for every subject. The tip of the tube was submerged $10 \mathrm{~cm}$ below the water surface, providing a PEP of
$10 \mathrm{~cm} \mathrm{H}_{2} \mathrm{O}$. For the PEP mask, an orifice resistor was connected to the expiratory limb of the T-valve. We used the resistor that resulted in a PEP of $\sim 10 \mathrm{~cm} \mathrm{H}_{2} \mathrm{O}$ as measured with the manometer.

During CPAP measurements, the anti-asphyxia housing end of the O2-RESQ system circuit or the Boussignac plastic tube was connected to the air-flow transducer. Both CPAP devices were connected to a rotameter. The threshold resistor was adjusted to $10 \mathrm{~cm} \mathrm{H}_{2} \mathrm{O}$, and for the flow resistor CPAP device, air flow was titrated to a CPAP of $10 \mathrm{~cm} \mathrm{H}_{2} \mathrm{O}$ using the same manometer as described above.

\section{Instructions}

When using the PEP devices, the subjects were instructed to take deep breaths, exhale slightly actively, and find a rhythm that would allow them to take 30 deep consecutive breaths. When using the CPAP devices, the subjects were asked to breathe normally and not to focus on their breathing.

\section{Study Protocol}

The study protocol is shown in Figure 3. After initial instructions, as described above, subjects practiced the IC maneuvers and breathing with all 4 devices. When they felt comfortable performing the 2 IC maneuvers and breathing with all 4 devices, the order in which they used each device was randomized (sealed envelopes).

After the initial IC maneuver, subjects performed 30 breaths with the selected device, and at the 31 st breath, they performed the second IC maneuver, still connected to the breathing device. After the second IC maneuver, subjects estimated their perceived exertion using the Borg category ratio (CR) 10 scale. ${ }^{22}$ Subjects were instructed to estimate their exertion during the 30 breaths, not during the second IC maneuver. To avoid carryover effects, subjects rested for 10 min between using each breathing device. During the measurement period, airway pressure and air flow were recorded continuously at $200 \mathrm{~Hz}$ using an MP30 system (Biopac Student Lab PRO 3.7.7, Biopac Systems).

\section{Calibration}

The calibration process has been described previously. ${ }^{23}$ Before measurements, a 2-point calibration procedure of pressure and air-flow transducers was performed. Pressure was calibrated at 0 and $10 \mathrm{~cm} \mathrm{H}_{2} \mathrm{O}$ using the manometer, and air flow was calibrated at 0 and $1 \mathrm{~L}$ using a $1-\mathrm{L}$ calibration syringe.

Because the air-flow transducer has a slight nonlinear property, it was further calibrated using a VT Plus gasflow analyzer (BioTek Instruments, Winooski, Vermont). 

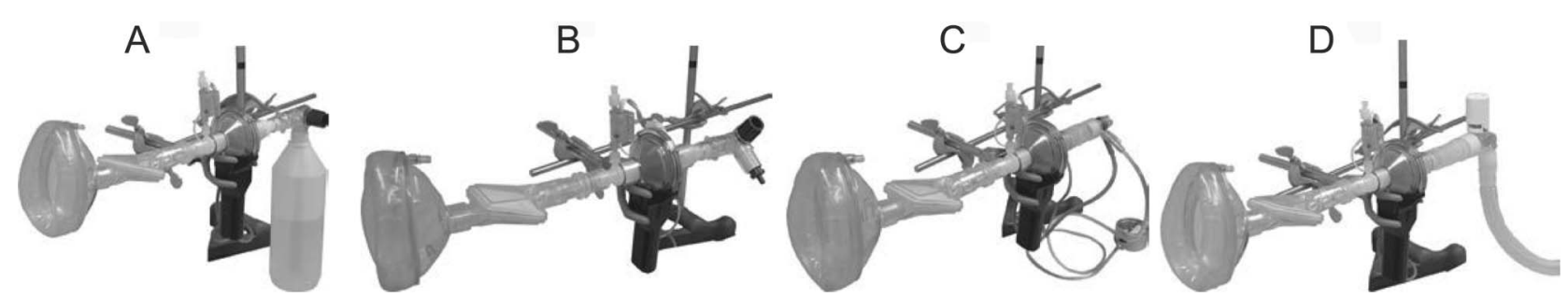

Fig. 2. Depiction of the experimental setup, comprising a face mask, bacterial filter, pressure transducer, airflow transducer, and breathing device. A: PEP bottle. B: PEP mask. C: Flow resistor CPAP device. D: Threshold resistor CPAP device.

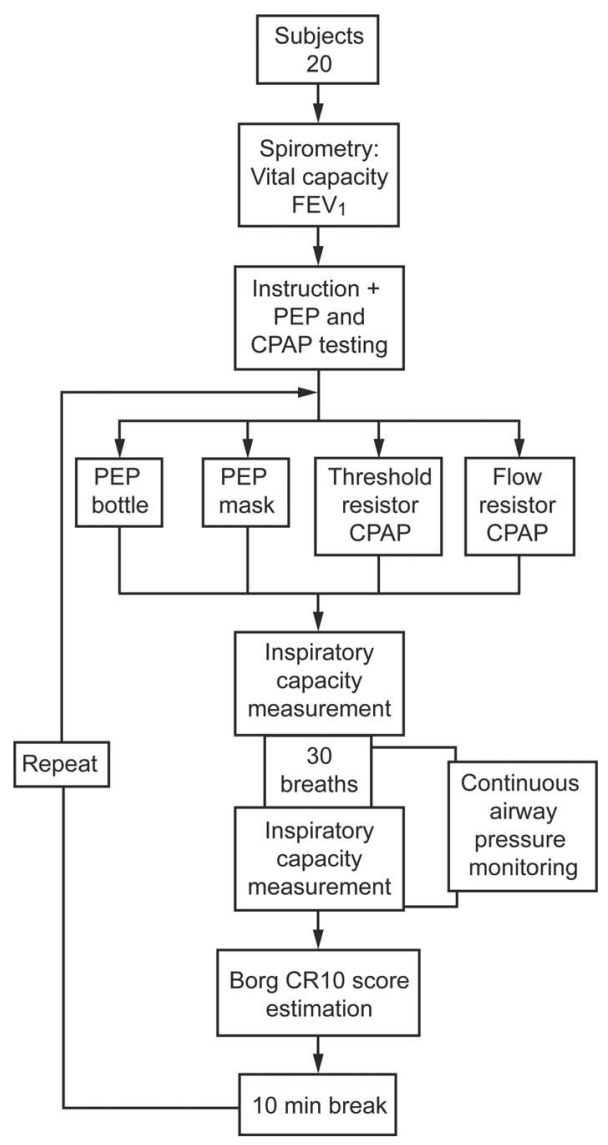

Fig. 3. Continuous airway pressure and air-flow monitoring. $\mathrm{PEP}=$ positive expiratory pressure; $\mathrm{CR}=$ category ratio.

In this calibration, air flow was increased stepwise at $0.2 \mathrm{~L} / \mathrm{s}$ in the interval between 0 and $3.0 \mathrm{~L} / \mathrm{s}$. These calibration values were used in the data processing described below.

\section{Data Processing}

Pressure and air-flow recordings were analyzed using MATLAB 2013b (MathWorks, Natick, Massachusetts). If baseline pressure and air-flow levels (measured during a period with no air flow) differed from zero, they were removed (adjusted to zero) from the pressure and air-flow signals before performing all subsequent analyses. The recalculated air-flow signal was interpolated with a cubic spline algorithm using data from the calibration of nonlinear effects described above.

Volumes were obtained through integration of the airflow signal, and any drift in the resulting volumes was removed (MATLAB detrend function). Air flow, pressure, and volumes were filtered using a fourth-order Butterworth $10-\mathrm{Hz}$ low-pass filter. Local maximum and minimum volumes were identified (findpeaks, an embedded function in MATLAB), and inspiratory and expiratory volumes were calculated. For every breath, median inspiratory and expiratory pressures and inspiratory and expiratory times were calculated and exported, together with inspiratory and expiratory volumes, to Excel (Microsoft, Redmond, Washington). To enable visual inspection, raw data (ie, pressure, air flow, and volumes) were down-sampled to $10 \mathrm{~Hz}$ and exported to Excel.

\section{IC Analysis}

Before the first IC maneuver, a baseline (based on the 3 breaths preceding the first IC maneuver) was identified. Similarly, a baseline was defined based on the 5 breaths preceding the second IC maneuver. For these selected breaths, end-expiratory volumes within a $99 \%$ CI were used to calculate the baseline. Primarily, all baselines were mathematically calculated and assessed by the authors. When in doubt, 2 blinded independent experts were asked to define the baseline by visual inspection. Of 160 baselines, 27 were manually determined by the 2 experts. A mean value of their assessment for each of the 27 baselines was used. As described previously, ${ }^{24}$ each baseline was used to adjust the corresponding IC values.

\section{Statistics}

All obtained data, except the Borg CR10 scores, were screened for normality using Shapiro-Wilk normality tests. Inspiratory time for the threshold resistor CPAP device was not normally distributed, but because the other 3 breathing devices were normally distributed, the outcome variable was assumed to be normally distributed. A linear mixed-effects model was used to compare the 4 breathing 
devices and for within-device comparisons. Outcome variables were IC (initial IC and the difference between the first and second IC), tidal volumes (inspiratory and expiratory), median pressures (inspiratory, expiratory, and the difference between the inspiratory and expiratory pressures), and time (inspiratory and expiratory). The breathing device (threshold resistor PEP, flow resistor PEP, threshold resistor CPAP, flow resistor CPAP) was specified as a repeated variable. The repeated covariance type was set to diagonal, and the fixed factor was the breathing device. The Bonferroni correction was used as an adjustment for multiple comparisons. A total of 9 different statistical analyses were performed using the linear mixedeffects model.

Results are presented as mean $\pm \mathrm{SD}$, intercept, $\beta$ coefficient, or $95 \%$ CI, except for Borg CR10 scores, which are reported as median (minimum to maximum) values. $P<.05$ was considered statistically significant. Statistical analyses were performed with SPSS 22.0 (IBM, Armonk, New York).

\section{Results}

\section{Demographics}

The 20 healthy subjects were $171 \pm 9 \mathrm{~cm}$ tall and weighed $75 \pm 14 \mathrm{~kg}$. Pulmonary function was normal: vital capacity, $4.48 \pm 0.95 \mathrm{~L}$ (119 $\pm 16 \%$ of predicted $)$; and $\mathrm{FEV}_{1}, 3.44 \pm 0.75 \mathrm{~L}(109 \pm 12 \%$ of predicted $)$.

\section{IC Measurements}

An initial IC maneuver was performed before breathing with each of the 4 devices. There was no significant difference $(P=.78)$ in the initial IC maneuvers between the devices. The initial IC maneuver measured $2.79 \pm 0.58 \mathrm{~L}$ with the PEP bottle, $2.88 \pm 0.70 \mathrm{~L}$ with the PEP mask, $2.94 \pm 0.62 \mathrm{~L}$ with the flow resistor CPAP device, and $2.77 \pm 0.55 \mathrm{~L}$ with the threshold resistor CPAP device. The second IC maneuver, performed directly after breathing with each device, showed lower ICs for all 4 breathing devices compared with the first IC maneuver (Fig. 4). The decrease in IC between the first and second measurement was $0.22 \pm 0.83 \mathrm{~L}$ for the PEP bottle, $0.86 \pm 0.64 \mathrm{~L}$ for the PEP mask, $1.20 \pm 0.48 \mathrm{~L}$ for the flow resistor CPAP device, and $0.84 \pm 0.72 \mathrm{~L}$ for the threshold resistor CPAP device. The decrease in IC was significant $(P<.001)$ for the PEP mask, flow resistor CPAP device, and threshold resistor CPAP device, but not for the PEP bottle $(P=.25)$. Nine subjects increased IC with the PEP bottle, one with the PEP mask, 2 with the threshold resistor CPAP device, and none with the flow resistor CPAP device. The subject who increased IC with the PEP mask also increased IC with the PEP bottle and threshold resistor CPAP device.

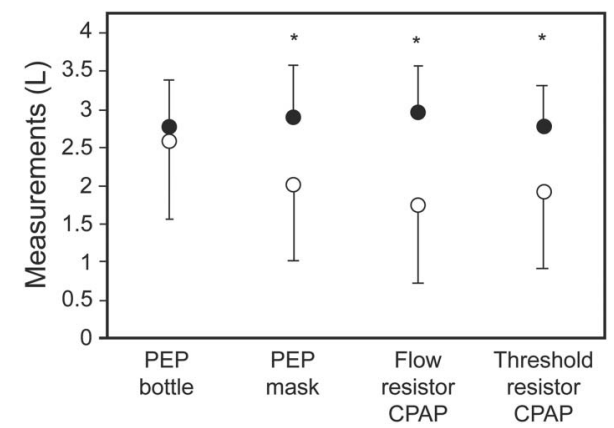

Fig. 4. Black circles represent initial inspiratory capacity (IC) maneuver, and white circles represent second IC maneuver. Data are presented as mean \pm SD. ${ }^{*} P<.001$ for the initial vs second IC maneuver. $\mathrm{PEP}=$ positive expiratory pressure.

The results describing the decrease in IC are based on estimates of fixed effects presented in Table 1.

\section{Inspiratory and Expiratory Pressures}

The presentation of significant differences is based on pairwise comparison after the Bonferroni correction. Airway pressure decreased during inspiration for all 4 devices. The mean of median inspiratory pressures was $-2.21 \pm 0.55 \mathrm{~cm} \mathrm{H}_{2} \mathrm{O}$ for the PEP bottle and $-2.26 \pm 0.59 \mathrm{~cm} \mathrm{H}_{2} \mathrm{O}$ for the PEP mask $(P>.99)$. The mean of median inspiratory pressures was $8.35 \pm 0.61 \mathrm{~cm} \mathrm{H}_{2} \mathrm{O}$ for the flow resistor CPAP device and $9.05 \pm 0.68 \mathrm{~cm} \mathrm{H}_{2} \mathrm{O}$ for the threshold resistor CPAP device. This difference was statistically significant $(P=.008)$. During expiration, airway pressure increased for all 4 devices. The mean of median expiratory pressures was $11.17 \pm$ $0.29 \mathrm{~cm} \mathrm{H}_{2} \mathrm{O}$ for the PEP bottle and $8.33 \pm 2.86 \mathrm{~cm} \mathrm{H}_{2} \mathrm{O}$ for the PEP mask $(P=.002)$. The mean of median expiratory pressures was $10.55 \pm 0.26 \mathrm{~cm} \mathrm{H}_{2} \mathrm{O}$ for the flow resistor CPAP device and $10.24 \pm 0.06 \mathrm{~cm} \mathrm{H}_{2} \mathrm{O}$ for the threshold resistor CPAP device $(P<.001)$. The difference between inspiratory and expiratory pressures was $13.38 \pm$ $0.71 \mathrm{~cm} \mathrm{H}_{2} \mathrm{O}$ for the PEP bottle and $10.59 \pm 3.01 \mathrm{~cm} \mathrm{H}_{2} \mathrm{O}$ for the PEP mask $(P=.004)$. The difference between inspiratory and expiratory pressures was significantly higher $(P=.001)$ for the flow resistor CPAP device $(2.20 \pm$ $0.77 \mathrm{~cm} \mathrm{H}_{2} \mathrm{O}$ ) then for the threshold resistor CPAP device $\left(1.19 \pm 0.68 \mathrm{~cm} \mathrm{H}_{2} \mathrm{O}\right)$ (Fig. 5).

\section{Breathing Pattern}

Mean inspiratory time did not differ significantly $(P=.40)$ between the 4 devices and was between $1.61 \pm 0.48 \mathrm{~s}$ (flow resistor CPAP device) and $1.91 \pm 0.56 \mathrm{~s}$ (PEP bottle). Mean expiratory time varied between $2.65 \pm 0.88 \mathrm{~s}$ (flow resistor CPAP device) and $4.66 \pm 1.65 \mathrm{~s}$ (PEP mask). The differences between each of the PEP devices and each of the CPAP devices were 


\section{Inspiratory Capacity to Measure EfFects of PEP AND CPAP on FRC}

Table 1. Mixed Model

\begin{tabular}{|c|c|c|c|c|c|c|c|c|c|c|}
\hline \multirow{3}{*}{ Outcome Variable } & \multirow{3}{*}{$n$} & \multirow{3}{*}{ Intercept } & \multicolumn{8}{|c|}{ Equipment } \\
\hline & & & \multicolumn{2}{|c|}{ PEP Bottle } & \multicolumn{2}{|c|}{ PEP Mask } & \multicolumn{2}{|c|}{$\begin{array}{l}\text { Flow Resistor } \\
\text { CPAP Device }\end{array}$} & \multicolumn{2}{|c|}{$\begin{array}{l}\text { Threshold Resistor } \\
\text { CPAP Device }\end{array}$} \\
\hline & & & $\beta$ Coefficient & $95 \% \mathrm{CI}$ & $\beta$ Coefficient & $95 \% \mathrm{CI}$ & $\beta$ Coefficient & $95 \% \mathrm{CI}$ & $\beta$ Coefficient & $95 \% \mathrm{CI}$ \\
\hline Initial IC, L* & 80 & $2.77 \dagger$ & 0.018 & -0.35 to 0.38 & 0.11 & -0.29 to 0.52 & 0.17 & -0.20 to 0.55 & 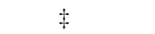 & $\ddagger$ \\
\hline Decrease in IC, $\mathrm{L} \S$ & 80 & NA & -0.22 & -0.61 to 0.17 & $-0.86 \dagger$ & -1.16 to -0.57 & $-1.20 \dagger$ & -1.43 to -0.98 & $-0.84 \dagger$ & -1.18 to -0.51 \\
\hline Volume in, $\mathrm{L}^{*}$ & 80 & $0.99 \dagger$ & 0.24 & -0.0098 to 0.48 & -0.040 & -0.25 to 0.17 & -0.14 & -0.35 to 0.063 & $\ddagger$ & $\ddagger$ \\
\hline Volume out, L* & 80 & $0.98 \dagger$ & 0.25 & -0.0063 to 0.50 & -0.050 & -0.27 to 0.17 & -0.15 & -0.36 to 0.061 & $\ddagger$ & $\ddagger$ \\
\hline $\mathrm{P}_{\mathrm{I}}, \mathrm{cm} \mathrm{H}_{2} \mathrm{O}^{*}$ & 80 & $9.05 \dagger$ & $-11.26 \dagger$ & -11.66 to -10.87 & $-11.31 \dagger$ & -11.72 to -10.90 & -0.70 & -1.12 to -0.29 & $\ddagger$ & $\ddagger$ \\
\hline $\mathrm{P}_{\mathrm{E}}, \mathrm{cm} \mathrm{H}_{2} \mathrm{O}^{*}$ & 80 & $10.24^{\dagger}$ & $0.93 \dagger$ & 0.79-1.07 & $-1.91 \|$ & -3.25 to -0.57 & $0.31 \dagger$ & 0.19-0.43 & $\ddagger$ & $\ddagger$ \\
\hline $\mathrm{P}_{\mathrm{I}}-P_{\mathrm{E}}, \mathrm{cm} \mathrm{H}_{2} \mathrm{O}^{*}$ & 80 & $1.19 \dagger$ & $12.2 \dagger$ & $11.7-12.6$ & $9.40 \dagger$ & 7.96-10.8 & $1.01 \dagger$ & $0.55-1.48$ & $\neq$ & $\ddagger$ \\
\hline $\mathrm{T}_{\mathrm{I}}, \mathrm{s}^{*}$ & 80 & $1.79 \dagger$ & 0.12 & -0.24 to 0.48 & -0.051 & -0.41 to 0.31 & -0.17 & -0.51 to 0.16 & $\ddagger$ & $\ddagger$ \\
\hline $\mathrm{T}_{\mathrm{E}}, \mathrm{s}^{*}$ & 80 & $2.71 \dagger$ & $1.75 \dagger$ & $0.99-2.50$ & $1.95 \dagger$ & $1.1-2.80$ & -0.056 & -0.61 to 0.50 & $\ddagger$ & $\ddagger$ \\
\hline $\begin{array}{l}\text { * Model dimension lev } \\
\dagger \text { Level of significance } \\
\text { † This parameter was } \\
\text { \& Model dimension lev } \\
\| \text { Level of significance } \\
\text { IC }=\text { inspiratory capac } \\
\mathrm{P}_{\mathrm{I}}=\text { mean median ins } \\
\mathrm{P}_{\mathrm{E}}=\text { mean median ex } \\
\mathrm{T}_{\mathrm{I}}=\text { inspiratory time } \\
\mathrm{T}_{\mathrm{E}}=\text { expiratory time } \\
\mathrm{NA}=\text { not applicable }\end{array}$ & $\begin{array}{l}\text { el } 9.1 \\
\text { of } 0 . \\
\text { et to } \\
\text { el } 8.1 \\
\text { of } 0.6 \\
\text { ty } \\
\text { pirato } \\
\text { irator }\end{array}$ & $\begin{array}{l}\text { Fixed effects } \\
001 . \\
\text { zero because } \\
\text { Fixed effects } \\
01 . \\
\text { ry pressure } \\
\text { y pressure }\end{array}$ & $\begin{array}{l}\text { is: intercept (1) anc } \\
\text { e it is redundant. } \\
\text { s: equipment (4); r }\end{array}$ & equipment (4); repeated & $\begin{array}{l}\text { d effect: subject (4) } \\
\text { 4). }\end{array}$ & & & & & \\
\hline
\end{tabular}

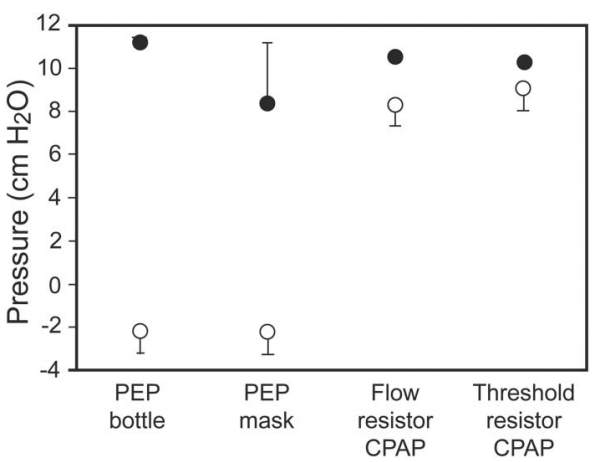

Fig. 5. Inspiratory and expiratory pressures during breathing with the 4 devices. White circles represent mean median inspiratory pressure, and black circles represent mean median expiratory pressure. Data are presented as mean \pm SD. Inspiratory pressure: $P=.008$ for the flow vs threshold resistor CPAP. Expiratory pressure: $P=.002$ for the positive expiratory pressure (PEP) bottle vs PEP mask, and $P<.001$ for the flow vs threshold resistor CPAP device. Difference between inspiratory and expiratory pressures: $P=.004$ for the PEP bottle vs PEP mask, and $P=.001$ for the flow vs threshold resistor CPAP device.

statistically significant $(P<.001)$.The difference in expiratory time between the 2 PEP devices and the difference in expiratory time between the 2 CPAP devices were not significant $(P>.99)$.

Both inspiratory and expiratory volumes were higher for the PEP bottle compared with the other 3 devices, reaching statistical significance only for the flow resistor CPAP device $(P=.008$ and .006 , respectively). Inspira- tory volume varied between $0.84 \pm 0.27 \mathrm{~L}$ with the flow resistor CPAP and $1.22 \pm 0.40 \mathrm{~L}$ with the PEP bottle. Expiratory volume varied between $0.83 \pm 0.27 \mathrm{~L}$ with the flow resistor CPAP device and $1.23 \pm 0.41 \mathrm{~L}$ with the PEP bottle (see Table 1).

\section{Perceived Exertion}

The subjects' median (minimum to maximum) perceived exertion (Borg CR10 scale) after 30 breaths with each of the 4 devices is presented in Figure 6. The perceived exertion was 2.75 (1-6) for the PEP bottle, $3.0(0.5-7)$ for the PEP mask, $2.0(0-5)$ for the flow resistor CPAP device, and $2.0(0.5-6)$ for the threshold resistor CPAP device.

\section{Discussion}

We investigated the effect of 4 breathing devices (2 PEP devices and 2 CPAP devices) on IC as an indirect measure of effects on FRC. After breathing with the PEP mask and the 2 CPAP devices, IC decreased (FRC increased). In contrast, almost half the group ( 9 of 20 subjects) increased IC after breathing with the PEP bottle.

When comparing the PEP devices and the CPAP devices separately, there was an indication that the decrease in IC was smaller for the threshold resistor device compared with the flow resistor device in both groups. This indication of a more pronounced decrease in IC with the flow resistor CPAP device compared with the threshold 


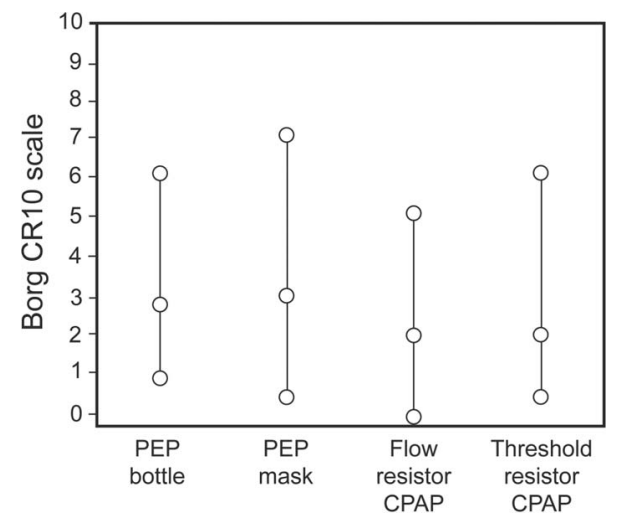

Fig. 6. Perceived exertion during 30 breaths with each of the 4 devices. The upper circles denote maximum values, the center circles denote median values, and the lower circles denote minimum values for each device. $\mathrm{PEP}=$ positive expiratory pressure; $\mathrm{CR}=$ category ratio.

resistor CPAP device is in concordance with the results from Andersson et al. ${ }^{6}$ They examined the effect of 3 different CPAP devices on end-expiratory lung volume (EELV), or FRC, in 14 healthy subjects and found that the increase in EELV was significantly higher with the Boussignac CPAP system compared with both the WhisperFlow CPAP device (IM-Medico, Stockholm, Sweden) and the Servo 300 ventilator (Maquet Critical Care, Solna, Sweden). In our study, the PEP mask and threshold resistor CPAP device produced a similar decrease in IC. To our knowledge, no such comparison has been done previously. Previous studies comparing the effects of CPAP and EPAP (PEP with a threshold resistor) on FRC have shown divergent results. ${ }^{13,14}$ No significant difference in effects on FRC was found in a study that compared CPAP with a blow bottle system. ${ }^{12}$ In contrast, our study suggests that a PEP device with a flow resistor like the PEP mask may be as effective as a CPAP device in decreasing IC.

IC has been used to measure changes in hyperinflation in subjects with COPD. ${ }^{15,16}$ If TLC is constant, a change in IC will correspond to an inverse change in EELV. ${ }^{24}$ TLC has been shown to be consistent in both healthy subjects 25 and in subjects with COPD ${ }^{26}$ during exercise. Because we used healthy subjects, we assumed that breathing with the different devices would not alter TLC. Therefore, a decrease in IC seen with each device could be interpreted as an increase in FRC. One reason to use IC as a measurement of changes in FRC is that FRC (or EELV) is difficult to measure in spontaneously breathing patients in the clinical setting. Advanced technical equipment is required for direct measurements of EELV. ${ }^{6}$

The effect of the PEP mask on FRC was investigated previously. Olsén et al ${ }^{27}$ investigated the effect of deep breathing without mechanical aid during PEP or inspiratory resistance PEP (IR-PEP) on breathing patterns (FRC) in obese and non-obese subjects using a body plethysmo- graph. The second FRC measurement was performed within 2 min after each breathing exercise had ended. No significant changes in FRC were found.

Bodin et $\mathrm{al}^{28}$ investigated breathing pattern during deep breathing without mechanical aid, during PEP, and during IR-PEP in subjects with tetraplegia (spinal cord lesion group) and healthy controls using a body plethysmograph. The second FRC measurement was performed similarly as in the study by Olsén et al. ${ }^{27}$ In contrast to their study, FRC increased significantly in the spinal cord lesion group during both PEP and IR-PEP. ${ }^{28}$ In the control group, FRC increased significantly during IR-PEP and decreased significantly during deep breathing without mechanical aid.

The PEP mask was also examined in 12 subjects with cystic fibrosis using a multiple-breath $\mathrm{N}_{2}$ washout method. ${ }^{8}$ The second FRC measurement was performed with direct continuation of PEP breathing. FRC increased significantly in 10 of 12 subjects. The effect of threshold resistor devices on FRC has also been investigated. Using a body plethysmograph, FRC was measured in 7 healthy nonsmoking males during breathing with an EPAP device (Emerson water column, JH Emerson, Cambridge, Massachusetts) at ambient airway pressure and at 5, 10, and $15 \mathrm{~cm} \mathrm{H}_{2} \mathrm{O}$. The authors reported that FRC increased by $6.3 \%$ for every rise in PEP. ${ }^{7}$ FRC was investigated in 8 subjects with cystic fibrosis during breathing at ambient pressure and at 5 and $15 \mathrm{~cm} \mathrm{H}_{2} \mathrm{O}$ (spring-loaded valve) using a body plethysmograph. ${ }^{29}$ FRC increased significantly at both PEPs, but the increase in FRC during breathing at $15 \mathrm{~cm} \mathrm{H}_{2} \mathrm{O}$ was significantly higher than during breathing at $5 \mathrm{~cm} \mathrm{H}_{2} \mathrm{O}$. After PEP breathing was ended, FRC rapidly returned to baseline values.

PEP devices with either a flow or threshold resistor can be used to increase FRC. However, changes in FRC seem to be short-lived. In our study, IC significantly decreased with the PEP mask (flow resistor), but not with the PEP bottle (threshold resistor). It is possible that the expiratory resistance produced by the water seal in the PEP bottle affects IC, and thus FRC, compared with other threshold resistors like the spring-loaded valve.

A difference between PEP and CPAP is that inspiratory pressure is lower than atmospheric pressure (negative) with PEP and higher than atmospheric pressure (positive) with CPAP. This discrepancy between the 2 methods causes the difference between inspiratory and expiratory pressures to be larger during PEP than during CPAP. To minimize work of breathing during CPAP, it is important to keep airway pressure at a constant level for the entire respiratory cycle. ${ }^{5}$ The difference between inspiratory and expiratory pressures was significantly larger for the flow resistor CPAP device compared with the threshold resistor CPAP device. We did not measure work of breathing in this study, but we used the Borg CR10 scale as a subjective measurement of the subjects' perceived exertion. The 
median estimated perceived exertion was quite low for all 4 devices, but the difference between the lowest and highest estimation with all 4 devices was rather large. The results for estimated perceived exertion for the PEP bottle and PEP mask were slightly higher than those reported in an earlier study examining both devices. ${ }^{3}$ The median perceived exertion after 3 sets of 10 breaths with each PEP device was 2.0 for the PEP bottle and 2.5 for the PEP mask $^{3}$ compared with 2.75 for the PEP bottle and 3.0 for the PEP mask after 30 consecutive breaths in our study. Although the total number of breaths for each PEP device was the same in both studies, the subjects found 30 consecutive breaths to be somewhat more strenuous than 3 sets of 10 breaths. In a study investigating the flow resistor CPAP device, perceived exertion when breathing at a CPAP of $10 \mathrm{~cm} \mathrm{H}_{2} \mathrm{O}$ for $10 \mathrm{~min}$ was examined. ${ }^{18}$ The subjects reported a median perceived exertion of 2.5 , which is somewhat higher than ours. However, the total time breathing with the flow resistor CPAP device was 10 min compared with 30 breaths in our study, which might explain our lower values.

Some methodological considerations have to be addressed. The intended expiratory pressure was $10 \mathrm{~cm} \mathrm{H}_{2} \mathrm{O}$ for all 4 breathing devices. The expiratory pressure was somewhat higher than $10 \mathrm{~cm} \mathrm{H}_{2} \mathrm{O}$ with the PEP bottle and lower with the PEP mask. To avoid influencing the subjects' breathing patterns during the tests, no further instructions were given after the initial training period.

Because we wanted to measure immediate effects of the 4 breathing devices, we performed the second IC maneuver with the subjects still connected to the device. Another reason for this measurement strategy was that PEPinduced changes in FRC have been shown to immediately return to normal values after a breathing session. ${ }^{28}$ Conditions during the second IC maneuver were the same for the 2 PEP devices and for the 2 CPAP devices. However, because the CPAP devices were running during the second IC maneuver, the condition for the PEP and CPAP measurements was not exactly the same, which might have affected the results.

During IC measurements, it is recommended that the tester should be able to view the volume-time plot to assess changes in breathing pattern and EELV at baseline before the IC maneuver. ${ }^{24}$ The equipment used in this study recorded air flow and airway pressure, but not volume. Volume was later obtained by integrating the flow signal. Therefore, it was not possible to determine in real time whether the baseline before the IC maneuvers could be considered stable enough for the subject to perform an IC maneuver.

The instructions used in this study are the same instructions that are used in the clinical setting when the aim with resistance breathing is to increase FRC. The fact that nearly half of the subjects increased IC (decreased FRC) when breathing with the PEP bottle makes us question the instructions patients receive regarding PEP breathing. In a study by Westerdahl et al, ${ }^{30}$ the immediate effect of deep breathing with and without mechanical aids (PEP bottle and IR-PEP) was investigated in subjects after cardiac surgery. All subjects were instructed to perform slow maximum inspirations. To minimize unintentional airway closure and alveolar collapse, the expiration was ended approximately at FRC. The results showed that there was a significant reduction in the atelectatic area with all 3 techniques. ${ }^{30}$ The subjects in our study were instructed to take deep breaths and to exhale slightly actively during PEP breathing. It is possible that the length of the expiratory phase and/or the muscle force used during expiration should be controlled to prevent a lowering of FRC, especially with the PEP bottle.

The increased number of breaths from 10 to 30 might have affected the breathing pattern differently when a threshold resistor was used compared with a flow resistor. We used 30 breaths also during CPAP breathing. CPAP breathing is usually done during a longer period of time. With CPAP devices, because the pressure changes between inspiration and expiration with the threshold resistor, CPAP is smaller than with the flow resistor. Therefore, breathing with the CPAP devices during a longer period of time could have affected the results. Notwithstanding, the measurements of changes in IC between the devices were done in healthy subjects and not in patients with reduced FRC.

\section{Conclusions}

Provided that TLC is constant, we found that measurements of changes in IC could be used as an indirect measure of changes in FRC. IC decreased significantly with 3 of the 4 breathing devices: the PEP mask and the flow and threshold resistor CPAP devices, but not with the PEP bottle. The magnitude of the decrease in IC was the same for the PEP mask and the threshold resistor CPAP device, suggesting that a PEP device with a flow resistor like the PEP mask may be as effective as a CPAP device in increasing FRC. With all 4 devices, the median estimated perceived exertion was quite low, but the range between lowest and highest estimations was rather large. These findings in healthy subjects merit further studies in subjects with decreased FRC, as seen in postoperative or ICU patients. Applied in the clinical setting, our experience from this study suggests that breathing instructions are crucial to achieve desired effects. Furthermore, the choice of breathing device has to be individualized and based on the patient's clinical status. Our results may facilitate such decisions. 


\section{Inspiratory Capacity to Measure EfFects of PEP AND CPAP on FRC}

\section{REFERENCES}

1. Banner MJ. Flow resistance of expiratory positive-pressure valve systems. Chest 1986;90(2):212-217.

2. Kacmarek RM, Dimas S, Reynolds J, Shapiro BA. Technical aspects of positive end-expiratory pressure (PEEP). Part I. Physics of PEEP devices. Respir Care 1982;27(12):1478-1489.

3. Sehlin M, Öhberg F, Johansson G, Winsö O. Physiological responses to positive expiratory pressure breathing: a comparison of the PEP bottle and the PEP mask. Respir Care 2007;52(8):1000-1005.

4. Fink JB. Positive pressure techniques for airway clearance. Respir Care 2002;47(7):786-796.

5. Gherini S, Peters RM, Virgilio RW. Mechanical work on the lungs and work of breathing with positive end-expiratory pressure and continuous positive airway pressure. Chest 1979;76(3):251-256.

6. Andersson B, Lundin S, Lindgren S, Stenqvist $\mathrm{O}$, Odenstedt Hergès $\mathrm{H}$. End-expiratory lung volume and ventilation distribution with different continuous positive airway pressure systems in volunteers. Acta Anaesthesiol Scand 2011;55(2):157-164.

7. Garrard CS, Shah M. The effects of expiratory positive airway pressure on functional residual capacity in normal subjects. Critical Care Med 1978;6(5):320-322.

8. Groth S, Stafanger G, Dirksen H, Andersen JB, Falk M, Kelstrup M. Positive expiratory pressure (PEP mask) physiotherapy improves ventilation and reduces volume of trapped gas in cystic fibrosis. Bull Eur Physiopathol Respir 1985;21(4):339-343.

9. Lindner KH, Lotz P, Ahnefeld FW. Continuous positive airway pressure effect on functional residual capacity, vital capacity and its subdivisions. Chest 1987;92(1):66-70.

10. Lopes AJ, Nery FP, Sousa FC, Guimarães FS, Dias CM, Oliveira JF, Menezes SL. CPAP decreases lung hyperinflation in patients with stable COPD. Respir Care 2011;56(8):1164-1169.

11. Monteiro MB, Berton DC, Moreira MA, Menna-Barreto SS, Teixeira PJ. Effects of expiratory positive airway pressure on dynamic hyperinflation during exercise in patients with COPD. Respir Care 2012;57(9):1405-1412.

12. Heitz M, Holzach P, Dittmann M. Comparison of the effect of continuous positive airway pressure and blowing bottles on functional residual capacity after abdominal surgery. Respiration 1985;48(3): 277-284.

13. Layon J, Banner MJ, Jaeger MJ, Peterson CV, Gallagher TJ, Modell $\mathrm{JH}$. Continuous positive airway pressure and expiratory positive airway pressure increase functional residual capacity equivalently. Chest 1986;89(4):517-521.

14. Schlobohm RM, Falltrick RT, Quan SF, Katz JA. Lung volumes, mechanics, and oxygenation during spontaneous positive-pressure ventilation: the advantage of CPAP over EPAP. Anesthesiology 1981; 55(4):416-422.

15. Dolmage TE, Goldstein RS. Repeatability of inspiratory capacity during incremental exercise in patients with severe COPD. Chest 2002;121(3):708-714.
16. O'Donnell DE, Lam M, Webb KA. Measurement of symptoms, lung hyperinflation, and endurance during exercise in chronic obstructive pulmonary disease. Am J Respir Crit Care Med 1998;158(5 Pt 1): 1557-1565.

17. Miller MR, Hankinson J, Brusasco V, Burgos F, Casaburi R, Coates A, et al. Standardisation of spirometry. Eur Respir J 2005;26(2):319-338.

18. Sehlin M, Törnell SS, Öhberg F, Johansson G, Winsö O. Pneumatic performance of the Boussignac CPAP system in healthy humans. Respir Care 2011;56(6):818-826.

19. Mestriner RG, Fernandes RO, Steffen LC, Donadio MV. Optimum design parameters for a therapist-constructed positive-expiratorypressure therapy bottle device. Respir Care 2009;54(4):504-508.

20. Leman P, Greene S, Whelan K, Legassick T. Simple lightweight disposable continuous positive airways pressure mask to effectively treat acute pulmonary oedema: randomized controlled trial. Emerg Med Australas 2005;17(3):224-230.

21. Mistraletti G, Giacomini M, Sabbatini G, Pinciroli R, Mantovani ES, Umbrello M, et al. Noninvasive CPAP with face mask: comparison among new air-entrainment masks and the Boussignac valve. Respir Care 2013;58(2):305-312.

22. Borg G. Borg's perceived exertion and pain scales. Campaign, IL: Human Kinetics; 1998:39-52.

23. Sehlin M, Brändström H, Winsö O, Haney M, Wadell K, Öhberg F. Simulated flying altitude and performance of continuous positive airway pressure devices. Aviat Space Environ Med 2014;85(11): 1092-1099.

24. Guenette JA, Chin RC, Cory JM, Webb KA, O'Donnell DE. Inspiratory capacity during exercise: measurement, analysis, and interpretation. Pulm Med 2013;2013:956081.

25. Stubbing DG, Pengelly LD, Morse JL, Jones NL. Pulmonary mechanics during exercise in normal males. J Appl Physiol 1980;49(3): 506-510.

26. Stubbing DG, Pengelly LD, Morse JL, Jones NL. Pulmonary mechanics during exercise in subjects with chronic airflow obstruction. J Appl Physiol 1980;49(3):511-515.

27. Olsén MF, Lönroth H, Bake B. Effects of breathing exercises on breathing patterns in obese and non-obese subjects. Clin Physiol 1999;19(3):251-257.

28. Bodin P, Kreuter M, Bake B, Olsén MF. Breathing patterns during breathing exercises in persons with tetraplegia. Spinal Cord 2003; 41(5):290-295.

29. van der Schans CP, van der Mark TW, de Vries G, Piers DA, Beekhuis H, Dankert-Roelse JE, et al. Effect of positive expiratory pressure breathing in patients with cystic fibrosis. Thorax 1991;46(4):252-256.

30. Westerdahl E, Lindmark B, Eriksson T, Hedenstierna G, Tenling A. The immediate effects of deep breathing exercises on atelectasis and oxygenation after cardiac surgery. Scand Cardiovasc J 2003;37(6): 363-367. 